\title{
An Historical Perspective on Digital Imaging in Transmission Electron Microscopy: Looking to the Future
}

\author{
Mark H. Ellisman
}

National Center for Microscopy and Imaging Research, Center for Research in Biological Systems, University of California at San Diego, La Jolla, CA 92093-0608

The digital revolution currently under way, as evidenced by the rapid development of the Internet and world-wide-web, is undoubtedly impacting the field of transmission electron microscopy (TEM). Digital imaging systems based on charge-coupled device (CCD) technologies, with pixel array sizes soon to exceed $4 \mathrm{k} \times 4 \mathrm{k}$, are available for TEM applications and offer many attractions. This presentation will frame the progression of digital imaging systems up to the present and beyond.

Charged coupled devices were invented in 1970 (Boyle and Smith 1970). They soon became the sensor of choice in many imaging applications, particularly in video cameras and camcorders. A driving force behind the development of large format CCDs, with array sizes greater than $1 \mathrm{k} \times 1 \mathrm{k}$, came from astronomy and the establishment of spaceborne observatories, where high resolution images were needed but it was impractical or impossible to use photographic film. Experimental CCD imaging systems for telescopes were built as early as 1976.

In transmission electron microscopy (TEM), there was a considerable delay in the adaptation of CCD technologies. The first experimental digital imaging system using CCDs was reported in 1982 (Roberts et al., 1982) where a 100 x 100 CCD array was directly exposed to $100 \mathrm{keV}$ electrons. Six years later in 1988, Spence and Zuo reported a 576 x 382 pixel CCD imaging system, which used an indirect detection scheme, involving an electron scintillator screen and an optical coupler, thereby avoiding some of the problems encountered with the direct detection scheme. Since then many other systems have been reported (Aikens et al. 1989; Chapman et al., 1989; Daberkow et al., 1991; Krivanek et al., 1991; Herrmann and Liu, 1992; Kujawa and Krahl, 1992; Fan and Ellisman, 1993; Krivanek and Mooney, 1993; Faruqi et al., 1995; Herrmann and Sikeler, 1995; Daberkow et al., 1996: Downing and Hendrickson, 1999, Fan et al. 2000). These systems have become invaluable for applications such as microscope automation, automated electron tomography, electron holography, protein crystallography, and telemicroscopy.

In this presentation, a brief history of digital imaging technology will be given to frame a discussion of emerging and future technologies that promise to align electron microscopy with the information technology advances of the $21^{\text {st }}$ century.

Aikens, R.S. Agard, D.A. and Sedat, J.W. (1989) Solid state imagers for microscopy. Methods Cell Biol. 29, 291

Boyle, W.S. and Smith, G.E. (1970) Charge-coupled semiconductor devices. Bell Systems Tech. J. 49, 587. 
Chapman, J.N., Craven, A.J. and Scott, C.P. (1989) Electron detection in the analytical electron microscope. Ultramicroscopy 28, 108.

Daberkow, I., Herrmann, K.-H., Lui, L. and Rau, W.D. (1991) Performance of electron image converters with YAG single-crystal screen and CCD sensor. Ultramicroscopy, 38, 215.

Daberkow, I., Herrmann, K.-H., Liu, L., Rau, W.D. and Tietz, H. (1996) Development and performance of a fast fiber-plate coupled CCD camera at medium energy and image processing system for electron holography. Ultramicroscopy, 64, 35.

Downing, KH; Hendrickson, FM. (1999) Performance of a 2K CCD camera designed for electron crystallography at $400 \mathrm{kV}$, Ultramicroscopy 75: 215-33.

Fan, G.Y., and Ellisman, M.H. (1993) High-sensitivity lens coupled slow-scan CCD camera for transmission electron microscopy. Ultramicroscopy 557.

Fan G.Y. et al. \& M.H. Ellisman (2000) Multiport-read-out frame-transfer 5 megapixel CCD imaging system for TEM applications, Ultramicroscopy, 199, 1-14.

Faruqi, A.R., Andrews, H.N. and Henderson, R. (1995) A high sensitive imaging detector for electron microscopy. Nucl. Instrum. Meth. Phys. Res. A, 367, 408.

Herrmann, K.-H. and Sikeler, R. (1995) Low-energy electron image converters for high resolution slow-scan CCD sensor. Optik, 98, 119.

Krivanek, O.L., Mooney, P.E. and Fan, G.Y. (1991) Slow-scan CCD cameras in transmission electron microscopy, Inst. Phys. Conf Ser. 119(119), 523.

Kujawa, S., and Krahl, D. (1992) Performance of a low-noise CCD camera adapted to a transmission electron microscope. Ultramicroscopy 46, 395.

Spence, J.C.H and Zuo, J.M. (1988) Large dynamic range, parallel detection system for electron diffraction and imaging. Rev Sci. Instrum. 59 (9), 2102. 